\title{
SIFAT KIMIA, FUNGSIONAL DAN REOLOGI PATI AREN FOSFAT PADA KOMBINASI KONSENTRASI PATI AREN DAN WAKTU REAKSI YANG BERBEDA
}

\section{CHEMICAL, FUNCTIONAL AND RHEOLOGY PROPERTIES OF PHOSPHORYLATED ARENGA STARCHES AT DIFFERENT ARENGA STARCH CONCENTRATION AND REACTION TIMES COMBINATIONS}

\author{
Abdul Rahim ${ }^{1 *}$, Gatot Siswo Hutomo ${ }^{1}$, Syahraeni Kadir ${ }^{1}$, Nur Alam ${ }^{1}$, Abd. Hamid ${ }^{1}$ dan Jusman ${ }^{2}$ \\ ${ }^{1}$ Program Studi Agroteknologi, Fakultas Pertanian, Universitas Tadulako. \\ ${ }^{2}$ Program Studi Kimia, Fakultas Matematika dan Ilmu Pengetahuan Alam, Universitas Tadulako, \\ Jln. Soekarno Hatta Km. 9 Palu, Sulawesi Tengah 94118, Indonesia.
}

\begin{abstract}
ABSTRAK
Tujuan penelitian adalah mendapatkan kombinasi optimal antara konsentrasi pati aren dan waktu reaksi pada sintesis pati aren fosfat. Sintesis pati aren fosfat menggunakan reagen sodium tripolifosfatserta pati aren 20 dan 30\% (b/v) denganvariasi waktu 30 dan 45 menit. Karakteristik kimia, fungsional dan reologi pati aren fosfat yang dianalisis diantaranya persen fosfat dan derajat substitusi (DS), pengikatan gugus fosfat menggunakan fourier transform infrared (FTIR), water dan oil holding capacity (WHC, OHC), daya mengembang dan kelarutan serta volume pemisahan emulsi. Hasil penelitian menunjukkan bahwa kombinasi konsentrasi pati aren 30\% dengan waktu reaksi 45 menit merupakan kombinasi optimum yang menghasilkan pati aren fosfat dengan kadar fosfat $(2,710 \%)$ dan DS 0,147 tertinngi. Spektra FTIR pati aren fosfat memiliki perubahan vibrasi daerah gugus $\mathrm{OH}$ yang menunjukkan terjadinya reaksi gugus fosfat dengan $\mathrm{OH}$ dalam molekul pati. WHC dan daya mengembang meningkat, namun kelarutan pati aren fosfat menurun seiring meningkatnya kombinasi pati aren dan waktu reaksi. Volume pemisahan emulsi paling stabil pada kombinasi konentrasi pati aren tertinggi dan waktu reaksi yang lama. Pati aren fosfat yang dihasilkan berpotensi digunakan sebagai emulsifier untuk pangan.
\end{abstract}

Kata Kunci : Pati aren fosfat,konsentrasi pati aren, waktu reaksi

\section{ABSTRACT}

The objectives of the study were to obtained the optimal combination of starch concentration and reaction time in the synthesis of phosphorylated arenga starches. Synthesis of phosphorylated arenga starches using sodium tripolyphosphate reagents and arenga starch 20 and $30 \%(b / v)$ with variations of time reaction 30 and $45 \mathrm{~min}$. Chemical, functional and rheological characteristics of phosphorylated arenga starcheswere investigated i.e. percent phosphate and degree of substitution (DS), binding of phosphate groups using FourierTransform Infrared (FTIR), water and oil holding capacity (WHC, $\mathrm{OHC}$ ), swelling power and solubility and emulsion separation volume. The results showed a combination of $30 \%$ arenga straches with a reaction time 45 min were optimal combination that to produced phosphorylated arenga starches with the highest of phosphate content (2.710\%) and DS 0.147. The FTIR spectra of phosphorylated arenga starches have been a change in vibration of $\mathrm{OH}$ groups that replace the reaction of phosphate groups with $\mathrm{OH}$ in starch molecules. WHC and swelling power increased, but solubility phosphorylated arenga starches decreased with the in increasing combination of arenga starch concentration and reaction time. The emulsion separation volume the most stable at the combination of highest arenga starch concentration and the long reaction time. Phosphorylated arenga starches which produced were used as emulsifiers for food aplication.

Keywords:Phosphorylated arenga starch, arenga starch concentration, reaction time 


\section{Pendahuluan}

Pati aren berasal dari pohon enau/aren (Arenga pinnata) yang diperoleh dengan cara ekstraksi batang aren yang telah ditebang sampai mendapatkan pati aren (Alam, 2006). Pati aren alami penggunaannya terbatas karena sifat fisikokimia dan fungsional belum memenuhi persyaratan untuk dapat dimanfaatkan sebagai produk pangan dan non pangan secara meluas. Untuk memperbaiki sifat-sifat tersebut, maka perlu dilakukan modifikasi kimiawi secara fosforilasi. Menurut Xu dkk. (2004) modifikasi pati dapat memperbaiki karakteristik fisik dan kimia, seperti meningkatkan stabilitas pati dan resistensi pati terhadap proses retrogradasi dengan derajat substitusi (DS) rendah $(0,01-0,30)$ yang dapat diaplikasikan untuk pangan.Dalam penelitian ini, dilakukan modifikasi kimia dengan cara mereaksikan pati aren dengan sodium tripolifosfat (STPP) sehingga menghasilkan pati aren fosfat.

Faktor-faktor yang berpengaruh dalam modifikasi secara fosforilasi adalah konsentrasi pati, jenis reagan yang digunakan, $\mathrm{pH}$, suhu dan waktu reaksi (Xu $d k k$., 2004). Pati aren fosfat sebagai bahan pangan fungsional dapat menggantikan tepung terigu sebagian dalam pembuatan aneka produk olahan pangan sehingga dapat menekan impor tepung terigu. Pati aren fosfat baik sebagai pangan fungsional memberikan efek fungsional bagi kesehatan manusia karena kandungan pati resisten yang ada. Penelitian tentang fosforilasi dengan perlakuan kombinasi konsentrasi pati dengan waktu reaksi hingga saat ini belum pernah dilakukan.

Oleh karena itu perlu dikaji lebih jauh pengaruh faktor-faktor tersebut terhadap proses sintesis pati aren fosfat. Bertolak dari permasalahan tersebut, maka dalam penelitian telah mengevaluasi faktor-faktor yang berpengaruh terhadap karakteristik kimia, fungsional dan reologi pati aren fosfat yaitu kombinasi jumlah pati dan waktu reaksi dalam sintesis pati aren fosfat.

\section{Metode Penelitian}

Bahan utama penelitian adalah pati aren yang diperoleh dari Desa Bulili Kecamatan

\footnotetext{
${ }^{*}$ Penulis Korespondensi.

E-mail: a_pahira@yahoo.com

Telp: +62-85397897809
}

Palolo Kabupaten Sigi Sulawesi Tengah. Bahanbahan kimia yang digunakan yaitu akuades, sodium tripolifosfat (STPP), $\mathrm{HCl}, \mathrm{NaOH}$, etanol berbagai macam konsentrasi, asam asetat, iodine, pelarut heksan, buffer fosfat, $\mathrm{KOH}$, minyak zaitun dan fenol. Peralatan yang digunakan diantaranya timbangan analitik, Sted Fast Stirer Model SL 2400, cabinet drier, pengaduk magnet, water bath shaker, sentrifuse, $\mathrm{pH}$ meter, mikropipet, shaking inkubator, erlenmeyer, tabung reaksi, pompa vakum, vortex (Ginie 2 Model G-S60E), agitator, akrilik glass plate, frame stainless steel, oven blower, rotari vakum evaporator dan Fourier Transform Infrared (FTIR) serta alat-alat gelas lainnya untuk analisis.

Penelitian menggunakan Rancangan Acak Lengkap dengan perlakuan kombinasi konsentrasi pati aren dan waktu reaksi yaitu P20W30 = pati aren 20\% dan waktu reaksi 30 menit, P20W45 = pati aren 20\% dan waktu reaksi 45 menit, $\mathrm{P} 30 \mathrm{~W} 30=$ pati aren $30 \%$ dan waktu reaksi 30 menit dan P30W45 = pati aren 30\% dan waktu reaksi 45 menit. Setiap perlakuan diulang 4 kali, sehingga terdapat 16 unit percobaan. Untuk mengetahui pengaruh perlakuan yang dicobakan maka dilakukan analisis ragam dan bila perlakuan menunjukan pengaruh nyata maka dilanjutkan dengan uji beda nilai jujur.

\section{Pembuatan pati aren fosfat}

Sintesis pati aren fosfat sesuai metode yang telah dikembangkan oleh Koo $d k k .2010$ dengan sedikit modifikasi. Variasi konsentrasi pati aren 20\% (20 g) dan 30\% (30 g) dilarutkan dalam $100 \mathrm{ml}$ aquades pada $\mathrm{pH} 10$ dengan penambahan $\mathrm{NaOH} \quad 3 \% \quad(\mathrm{~b} / \mathrm{v})$ sambil ditambahkan STPP 4\% secara bertetes-tetes sambil tetap diaduk menggunakan stirrer. Proses berikutnya adalah suspensi diinkubasi pada environmental orbital shaker suhu $40^{\circ} \mathrm{C}$ dengan kecepatan agitator $200 \mathrm{rpm}$ dengan variasi lama waktu 30 dan 45 menit. Kemudian $\mathrm{pH}$ diatur sampai 5.5 menggunakan $\mathrm{HCl}$ dan disaring dengan penyaring vakum. Endapan pati yang diperoleh dicuci dengan air sebanyak $150 \mathrm{ml}$ sebanyak 5 kali. Selanjutnya pati dikeringkan dengan cabinet drier pada suhu $50^{\circ} \mathrm{C}$ selama 24 jam, digiling dan diayak untuk dianalisis. Variabel pengamatan pati aren fosfat yang dianalisis meliputi: (i) persen fosfat dan derajat substitusi (DS) dengan metode titrasi (ii) pengikatan gugus fosfat menggunakan spektra fourier transform infrared (FTIR), (iii) water dan oil holding capacity (WHC-OHC), (iv) daya 
mengembang dan kelarutandan (v) volume pemisahan emulsi.

\section{Pengamatan}

Analisis fosfat dan derajat substitusi

Kadar fosfat dan derajat substitusi (DS) ditentukan berdasarkan metode oleh Singh $d k k$. (2004). Sebanyak 1,0 g patifosfat dimasukkan ke dalam erlenmeyer $250 \mathrm{ml}$ dan kemudian ditambah dengan $50 \mathrm{ml}$ etanol $75 \%$. Dispersi pati dipanaskan dan diagitasi pada suhu $50^{\circ} \mathrm{C}$ di dalam waterbath selama 30 menit dan kemudian didinginkan pada suhu kamar. Setelah dingin, ke dalam suspensi pati ditambahkan $40 \mathrm{ml}$ larutan 0,5 M KOH dan kemudian digoyang dengan menggunakan shaker selama 30 menit pada suhu kamar. Setelah di-shaker, kelebihan alkali dititrasi dengan menggunakan larutan $0,5 \mathrm{M} \mathrm{HCl}$ dan dengan menggunakan phenolphthatelin sebagai indikator sampai warna merah muda menghilang. Sebagai blanko digunakan pati aren alami. Jika $\mathrm{W}=$ berat substituen yang terikat dan menggantikan gugus hidrogen pada gugus $\mathrm{OH}$ (\% berat), $\mathrm{M}=$ berat molekul substituen (gugus fosfat $=31), \mathrm{W} / \mathrm{M}=$ jumlah mol substituen, $1 \mathrm{x}$ $\mathrm{W} / \mathrm{M}=$ total berat hidrogen $(\%), 162=$ berat molekul satuan glukosa (anhidro, $\mathrm{C}_{6} \mathrm{H}_{10} \mathrm{O}_{5}$ ) dan $(100-\mathrm{W}+1 \mathrm{x} \mathrm{W} / \mathrm{M}) / 162=$ berat mol satuan glukosa, maka:

$\%$ Fosfat $(\mathrm{W})=\frac{[\text { (blanko }- \text { sampel }) \mathrm{ml} \cdot \mathrm{MHCl} .0,031.100]}{\text { Berat kering sampel }(\mathrm{g})}$

$\mathrm{DS}=\frac{162 \mathrm{~W}}{100 \mathrm{M}-(\mathrm{M}-1) \mathrm{W}}$

Analisis pengikatan gugus fosfat

Spektrum FTIR pati alami dan pati fosfat diukur menggunakan metode $\mathrm{KBr}$ seperti yang dikemukakan oleh Pushpamalar dkk. (2006). Sampel dicampur dengan $\mathrm{KBr}$ dengan perbandingan pati $/ \mathrm{KBr}=1: 4$. Campuran tersebut dimampatkan untuk mendapatkan pelet yang transparan dan kemudian sampel dikenai sinar infrared dengan spektrometer (MIDAC, prospect 269, Costa Mesa, CA, USA). Setiap spektrum dianalisis dalam kisaran resolusi $500-4000 \mathrm{~cm}^{-1}$.

Analisis water dan oil holding capacity

WHC dan OHC pati alami dan pati fosfat diukur menggunakan metode Larrauri $d k k$. (1996). Dua puluh lima mililiter akuades atau minyak zaitun komersial ditambahkan ke $250 \mathrm{mg}$ sampel kering, diaduk dan dibiarkan pada suhu kamar selama $1 \mathrm{jam}$. Setelah sentrifugasi residu ditimbang,WHC dan OHC dihitung sebagai g air atau minyak per $\mathrm{g}$ sampel kering.
Analisis daya mengembang dan kelarutan

Daya mengembang dan kelarutan ditentukan berdasarkan metode yang dikemukakan oleh Adebowale $d k k$. (2009). Pati disuspensikan dengan akuades $(1 \%, \mathrm{~b} / \mathrm{v})$ dengan tabung reaksi yang telah diketahui beratnya $\left(\mathrm{W}_{1}\right)$. Kemudian dipanaskan pada penangas air suhu $80^{\circ} \mathrm{C}$ selama 30 menit, lalu didinginkan hingga suhu ruang. Selanjutnya disentrifugasi pada 3400 rpm selama 15 menit, sehingga terpisah residu dan supernatan. Residu dan air yang tertahan setelah disentrifugasi kemudian ditimbang $\left(\mathrm{W}_{2}\right)$. Daya mengembang $(\mathrm{g} / \mathrm{g})=\left(\mathrm{W}_{2}-\mathrm{W}_{1}\right) /$ Berat pati. Supernatan $(5 \mathrm{ml})$ dikeringkan hingga berat konstan pada suhu $110^{\circ} \mathrm{C}$. Residu yang terdapat setelah dikeringkannya supernatan, menunjukkan jumlah pati yang terlarut dalam air (\%).

Analisis volume pemisahan emulsi

Volume pemisahan emulsi diukur dengan menggunakan metode yang dikembangkan oleh Perrechil dan Cunha (2010). Sampel ditimbang $1,0 \mathrm{~g}$ lalu ditambah akuades $10 \mathrm{ml}$ dan Tween 80 $1 \mathrm{ml}$ dimasukkan dalam tabung reaksi berskala. Campuran tersebut dipanaskan pada suhu $90^{\circ} \mathrm{C}$ selama 10 menit kemudian disimpan dalam suhu kamar. Diukur volume pemisahan emulsi pada suhu kamar mulai jam ke-0, 24, 48 dan 72 beserta dihitung persetase volume pemisahannya.

\section{Hasil dan Pembahasan}

\section{Kadar fosfat dan DS}

Kadar fosfat dan DS pada kombinasi konsentrasi pati aren dan lama waktu reaksi dapat dilihat pada Gambar 1. Hasil penelitian menunjukkan bahwa kombinasi konsentrasi pati aren dan lama waktu reaksi berpengaruh nyata terhadap kadar fosfat dan DS. Kadar fosfat dan DS meningkat seiring dengan meningkatnya kombinasi pati aren dan waktu reaksi.

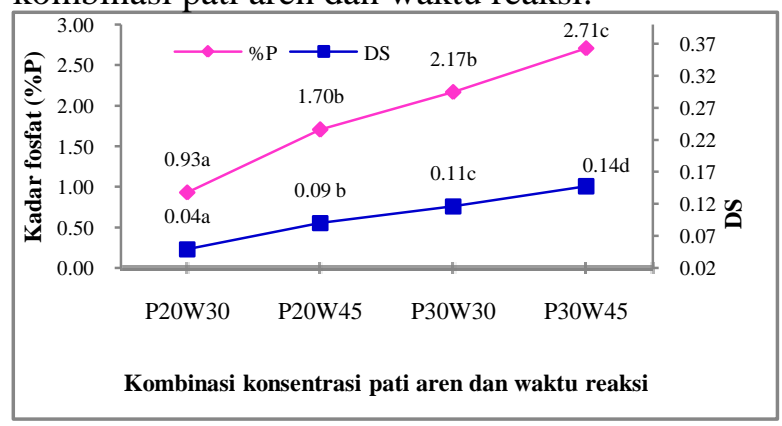

Gambar 1. Nilai rata-rata kadar fosfat dan DS pada kombinasi konsentrasi pati aren dan waktu reaksi

Pola peningkatan kadar fosfat dan DS bersifat linier. Kondisi optimal sintesis pati aren 


\section{Jurnal Pengolahan Pangan 3 (2) 60-65}

fosfat terjadi pada kombinasi konsentrasi pati aren 30\% dengan waktu reaksi selama 45 menit, karena menghasilkan kadar fosfat $(2,71 \%)$ dan DS $(0,147)$ yang tertinggi. Beberapa hasil penelitian sebelumnya menyatakan bahwa semakin lama waktu reaksi (dalam jangka waktu tertentu) maka gugus fosfat yang mensubstitusi gugus hidroksil semakin tinggi, yang disebabkan oleh lamanya waktu kontak antara monosodium fosfat dengan pati sehingga mengurangi kekuatan ikatan hidrogen pada pati (Teja $d k k$., 2008). Menurut Clark (2002), berdasarkan teori tumbukan, apabila frekuensi terjadinya benturan antara partikel meningkat, maka akan meningkatkan kecepatan reaksi.

\section{Pengikatan gugugs fosfat}

Spektra FTIR pati aren alami dan pati aren fosfat dari berbagai kombinasi pati aren dan waktu reaksi (P20W30, P20W45, P30W30 dan P30W45) disajikan pada Gambar 2. Spektra pati aren alami memiliki puncak pada bilangan gelombang 3510, 2932 dan $1651 \mathrm{~cm}^{-1}$ yang masing-masing merupakan vibrasi dari gugus $\mathrm{OH}$, metilen $\left(\mathrm{CH}_{2}\right)$, dan pengikatan air $\left(\mathrm{H}_{2} \mathrm{O}\right)$.

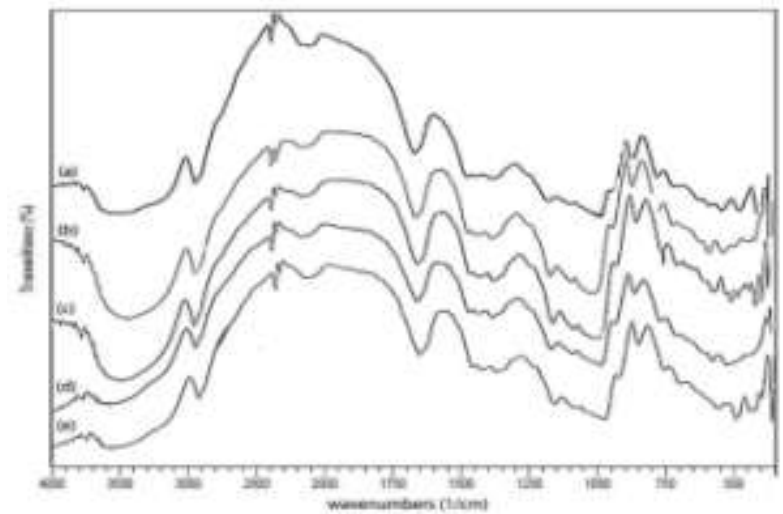

Gambar 2. Spektra FTIR pati aren alami (a), pati aren fosfat dengan P20W30 (b), P20W45 (c), P30W30 (d) dan P30W45 (e).

Spektra pati aren fosfat memiliki perubahan vibrasi daerah gugus $\mathrm{OH}$ pada bilangan gelombang $3502 \mathrm{~cm}^{-1}$ (P20W30), 3471 $\mathrm{cm}^{-1}$ (P20W45), $3425 \mathrm{~cm}^{-1}$ (P30W30) dan 3417 $\mathrm{cm}^{-1}$ (P30W45) yang mengindikasikan adanya inkorporasi gugus fosfat dalam molekul pati aren. Menurut Rahim $d k k$. (2012) bahwa spektra pati aren alami memiliki puncak pada bilangan gelombang 3426, 2932 dan $1651 \mathrm{~cm}^{-1}$ yang masing-masing merupakan vibrasi $\mathrm{O}-\mathrm{H}$ dari gugus hidroksi, $\mathrm{C}-\mathrm{H}$, dan pengikatan $\mathrm{H}_{2} \mathrm{O}$ dalam molekul pati.
e-ISSN : 2621-6973

p-ISSN : 2527-5631

\section{Water dan oil holding capacity}

Water dan oil holding capacity (WHCOHC) pada kombinasi konsentrasi pati aren dan lama waktu reaksi disajikan pada Gambar 3. Hasil penelitian menunjukkan bahwa kombinasi konsentrasi pati aren dan lama waktu reaksi berpengaruh nyata terhadap WHC, tetapi tidak berpengaruh nyata terhadap OHC. WHC pati aren fosfat meningkat seiring dengan bertambahnya kombinasi pati aren dan waktu reaksi, sedangkan $\mathrm{OHC}$ relatif konstan.

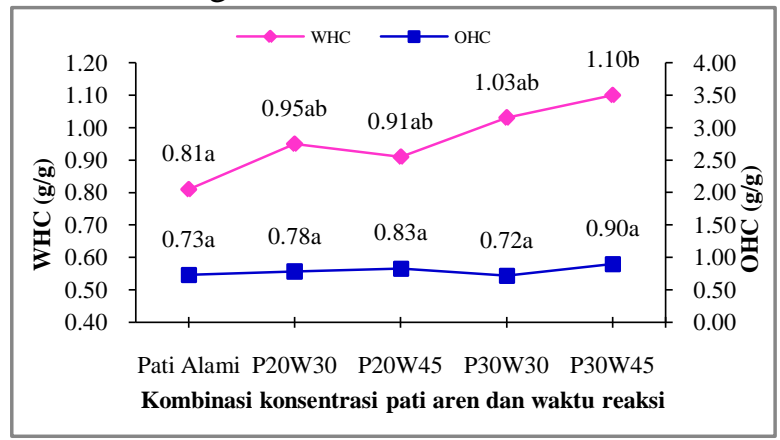

Gambar 3. Nilai rata-rata WHC dan OHC pada kombinasi konsentrasi pati aren dan waktu reaksi

Data ini menunjukkan bahwasifat hidrofilik cenderung lebih baik setelah fosforilasi. Peningkatan WHC terjadi karena adanya gugus fungsional ester fosfor pada pati aren fosfat yang memfasilitasi kemampuan menahan air dan minyak sehingga pati fosfat ini memiliki potensi sebagai emulsifiyer. Menurut Adebowale $d k k$.(2006) bahwa WHC pati sword bean asetat (DS0,14) lebih besar dibanding pati alami, sementara Garg dan Jana (2011) melaporkan bahwa WHC pati jagung butirat bertambah sampai DS 0,30.

\section{Daya mengembang dan kelarutan}

Daya mengembang dan kelarutan pada kombinasi konsentrasi pati aren dan lama waktu reaksi dapat dilihat pada Gambar 4. Hasil penelitian menunjukkan bahwa kombinasi konsentrasi pati aren dan lama waktu reaksi tidak berpengaruh nyata terhadap daya mengembang, tetapi berpengaruh nyata terhadap kelarutan. Kelarutan pati aren fosfat menurun seiring dengan bertambahnya kombinasi pati aren dan waktu reaksi. Kelarutan pati alami berbeda nyata dengan pati aren fosfat pada kombinasi pati aren dan waktu reaksi P20W45, P30W30 dan P30W45 tetapi tidak berbeda nyata dengan P20W30, sedangkan kelarutan antara pati aren fosfat P20W45, P30W30 dan P30W45 tidak berbeda nyata. 


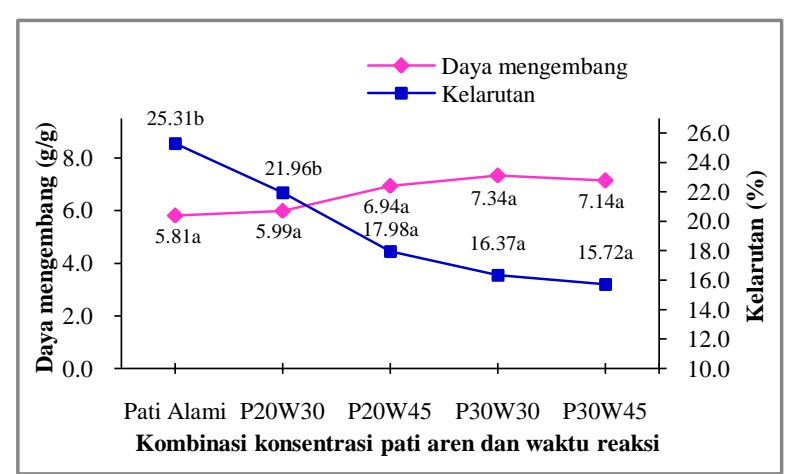

Gambar 4. Nilai rata-rata daya mengembang dan kelarutan pada kombinasi konsentrasi pati aren dan waktu reaksi

Menurut Yuliana (2011) bahwa ikatan fosfat pada polimer pati berpotensi mencegah rekasi pada polimer satu dengan lainnya, mengurangi infusi air dan dapat memperkuat ikatan hidrogen antar rantai polimer molekul pati sehingga dapat menghambat terjadinya pati mengembang dan mencegah kelarutan molekul pati.

\section{Volume pemisahan emulsi}

Volume pemisahan emulsi pati aren fosfat pada beebagai kombinasi konsentrasi pati aren dan waktu reaksi yang disimpan pada 24, 48 dan 72 jam disajikan pada Gambar 5. Variasi kombinasi konsentrasi pati alami dan waktu reaksi pati aren fosfat berpengaruh nyata terhadap volume pemisahan emulsi. Pati aren alami memiliki pemisahan emulsi yang paling tinggi, sedangkan pati aren fosfat hasil kombinasi konsentrasi pati alami 30\% dan waktu reaksi 45 menit (P30W45) paling rendah pemisahan emulsinya.

Apabila kombinasi konsentrasi pati aren tinggi dengan waktu reaksi yang lama dalam sintesis pati aren fosfat maka kemampuan dalam membentuk lapisan film juga akan semakin besar sehingga dapat memperkecil terjadinya pemisahan fase emulsi dan sebaliknya.

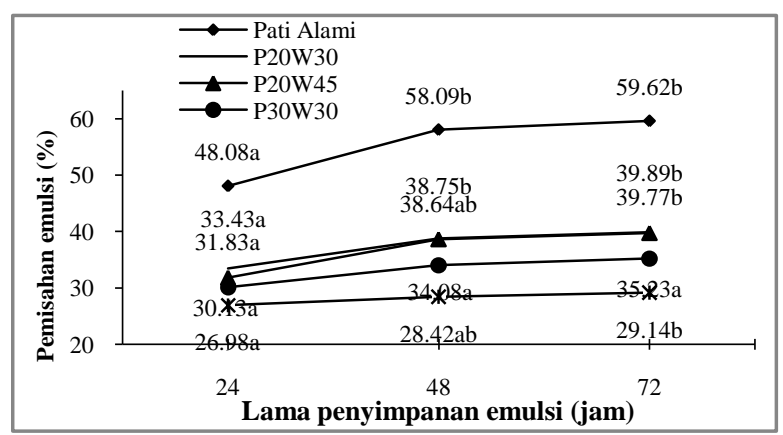

Gambar 5. Nilai rata-rata volume pemisahan emulsi pada lama penyimpanan emulsi berdasarkan kombinasi konsentrasi pati aren dan waktu reaksi
Menurut Perrachil dan Cunha (2010) bahwa pati asetat memiliki kestabilan emulsi yang lebih baik dibandingkan dengan pati alami karena memiliki gugus asetil yang menyebabkan molekul pati bersifat hidrofilik dan hidrofobik.

\section{Kesimpulan}

Kombinasi konsentrasi pati aren dan waktu reaksi yang optimal pada proses fosforilasi pati diperoleh pada pati aren $30 \%(\mathrm{~b} / \mathrm{v})$ dengan waktu reaksi 45 menit. Fosforilasi pati aren menghasilkan pati aren fosfat yang memiliki karakteristik kimia, fungsional dan reologi yang lebih baik dibanding dengan pati alaminya sehingga dapat digunakan lebih luas untuk pangan dan non pangan.

\section{Ucapan Terima Kasih}

Terima kasih disampaikan kepada Kementerian Riset, Teknologi dan Pendidikan Tinggi yang telah mendukung pendanaan penelitian melalui skema penelitian berbasis kompetensi tahun 2018.

\section{Daftar Pustaka}

Adebowale, K.O., Afolabi, T.A. \& Olu-Owolabi, B.I. 2006. Functional, physicochemical and retrogradation properties of sword bean (Canavalia gladiata) acetylated and oxidized starches. Carbohydrate Polymers. 65: 93-101

Alam, N. 2006. Potensi batang aren sebagai sumber pati untuk instant starch noodle. Jurnal Agroland. 7: 121-128.

Clark, J. 2002. Factors influencing rate of reaction. http://www.chemguide.co.uk/ physical/basicrates/arrhenius.html\#top.

Garg, S. \& Jana, A. M. 2011. Characterization and evaluation of acylated starch with different acyl groups and degrees of substitution. Carbohydrate Polymers.83: $1623-1630$.

Koo, S. H, Lee, K. Y. \& Lee, H. G. 2010. Effect of cross-linking on the physicochemical and physiological properties of corn starch. Food Hydrocolloids. 24: 619-625.

Larrauri, J.A., Ruperez, P., Borroto, B. \& SauraCalixto, S. 1996. Mango peels as a new tropical fibre: Preparation and characterization. Lebensm Wissenschaft und Technology. 29: 729-733. 
Perrachil, F.A. \& Cunha, R.L., 2010. Oil-inwater emulsions stabilized by sodium caseinate : Influence of $\mathrm{pH}$, high-pressure homogenization and locust bean gum addition. Journal of Engineering. 97: 441448.

Pushpamalar, V. Langford, S.J., Ahmad, M. \& Lim, Y.Y. 2006. Optimization of reaction conditions for preparing carboxymethyl cellulose from sago waste. Carbohydrate Polymers. 64: 312-318.

Rahim, A., Haryadi, Cahyanto, M. N. \& Pranoto, Y. 2012. Characteristics of butyrylated arenga starch prepared at different reaction time and butyric anhydride concentration. International Food Research Journal. 19(4): 1655-1660.
Singh, N., Chawla, D. \& Singh, J. 2004. Influence of acetic anhydride on physicochemical, morphological and thermal properties of corn and potato starch. Food Chemistry. 86: 601-608.

Teja, A. W., Ignatius, S. P., Aning Ayucitra, Laurentia E. K. \& Setiawan. 2008. Karakteristik pati sagu dengan metode modifikasi asetilasi dan Cross-linking. Jurnal Teknik Kimia Indonesia. 7(3): 836843.

Xu, Y., Miladinove, V. \& Hanna, M.A. 2004. Synthesis and characterization of starch acetates with high substitution. Cereal Chemistry. 81(6): 735-740.

Yuliana. 2011. Karakterisasi pragelatinisasi pati singkong fosfat yang dibuat dengan menggunakan natrium tripolifosfat sebagai eksipien dalam sediaan farmasi. Skripsi. Universitas Indonesia. 